Proceedings of the 2000 Hydrogen Program Review

NREL/CP-57028890

\title{
CATALYTICALLY ENCHANCED SYSTEMS FOR HYDROGEN STORAGE
}

\author{
Craig M. Jensen and Satoshi Takara \\ Department of Chemistry \\ University of Hawaii \\ Honolulu, HI 96822
}

\begin{abstract}
A new catalyst has been discovered for the rehydriding of $\mathrm{NaH}$ and $\mathrm{Al}$ to NaAlH4. The kinetics of this process in the presence of this catalyst is improved by a factor of $\sim 5$ over that of $\mathrm{Ti} / \mathrm{Zr}$ doped hydride. The problem of hydrocarbon contamination of the hydrogen evolved from catalytically enhanced $\mathrm{NaAlH}_{4}$ can be eliminated by doping the hydride with $\mathrm{TiCl}_{4}$ in place of $\mathrm{Ti}(\mathrm{OBu}) 4$. Partial substitution of sodium cation by potassium results in a lowering of the plateau pressure associated with the dehydriding of $\mathrm{X}_{3} \mathrm{AlH}_{6}$ to $\mathrm{XH}$ and $\mathrm{Al}$.
\end{abstract}

\section{Introduction}

For decades, hydrogen has been targeted as the utopian fuel of the future due to its abundance and environmental friendliness. A major difficulty in the utilization of hydrogen as a fuel is the problem of onboard hydrogen storage. High pressure and cryogenic hydrogen storage systems are impractical for vehicular applications due to safety concerns and volumetric constraints. This has prompted an extensive effort to develop solid hydrogen storage systems for vehicular application. Metallic hydrides (Sandrock et al. 1992; Sandrock 1995), activated charcoal (Carpetis and Peshka, 1980; Agarwal et al., 1987) and carbon nanotubules (Dillon et al., 1997) have been investigated as hydrogen carriers. Unfortunately, despite decades of extensive effort, especially in the area of metallic hydrides, no material has been found which as has the combination of a high gravimetric hydrogen density, adequate hydrogen dissociation energetics, and low cost required for commercial vehicular application (Suda and Sandrock, 1994). The 
dehydrogenation of $\mathrm{NaAlH}_{4}$ is known to occur by a multistep process involving the reactions seen in equations 1 and 2 (Dymova et. al., 1975). This process is thermodynamically mically favorable at moderate

$$
\begin{array}{lll}
3 \mathrm{NaAlH}_{4} & -------->>\mathrm{Na}_{3} \mathrm{AlH}_{6}+2 \mathrm{Al}+3 \mathrm{H}_{2} \\
\mathrm{Na}_{3} \mathrm{AlH}_{6} & -------->> & 3 \mathrm{NaH}+\mathrm{Al}+3 / 2 \mathrm{H}_{2}
\end{array}
$$

temperatures. However, it is characterized by very slow kinetics (Dymova et. al., 1975) and reversibility only under severe conditions (Dymova et. al., 1974). Thus despite favorable thermodynamics and a high available hydrogen weight percentage, $\mathrm{NaAlH}_{4}$ was precluded from consideration as a potential hydrogen storage material until it was recently discovered that titanium doping of $\mathrm{NaAlH}_{4}$ significantly enhances the kinetics of hydrogen desorption and renders the dehydriding process reversible under moderate conditions (Bogdanovic and Schwickardi, 1997; Jensen et al., 1999; Zidan et al., 1999). Bogdanovic found that the onset of the initial dehydriding was lowered by $\bullet 50 \cdot \mathrm{C}$ upon titanium doping by evaporation of an ether suspension of $\mathrm{NaAlH}_{4}$ which contained $2 \mathrm{~mol}$ $\%$ of titanium tetra- $n$-butoxide, $\mathrm{Ti}\left(\mathrm{OBu}^{\mathrm{n}}\right)_{4}$ (Bogdanovic and Schwickardi, 1997). We subsequently found that homogeni-zation of $\mathrm{NaAlH}_{4}$ with $\mathrm{Ti}\left(\mathrm{OBu}^{\mathrm{n}}\right) 4$ resulted in a material that undergoes rapid dehydriding at temperatures as low as $100 \cdot \mathrm{C}$ and proceeds at an appreciable rate even at $80 \bullet^{\circ} \mathrm{C}$ (Jensen et al., 1999; Zidan et al., 1999). The cyclable hydrogen capacity is also improved in the advanced titanium doped material. Over $4.0 \mathrm{wt} \%$ hydrogen can be evolved through 10 dehydriding-rehydriding cycles. We have found that the dehydriding of $\mathrm{NaAlH}_{4}$ is also kinetically enhanced by doping the hydride with zirconium through our procedure (Jensen et al., 1999; Zidan et al., 1999). The zirconium doped material has a further improved, $4.5 \mathrm{wt} \%$ cyclable hydrogen capacity. In contrast to the titanium doped material, the catalytic effect is most pronounced for the second rather than the first dehydriding process. We have found that titanium and zirconium can act in concert to optimize dehydriding/rehydriding kinetics while achieving a $4.5 \mathrm{wt} \%$ cyclable hydrogen capacity. These findings represented a breakthrough in the application of this class of hydrides to hydrogen storage and suggested that our materials might be developed as practical onboard hydrogen carriers. In order to assess this possibility, we have extended our studies to large scale $(100 \mathrm{~g})$ hydrogen cycling tests that are being conducted in collaboration with Sandia National Laboratory. Additionally, Honda, General Motors, Toyota, Japan Steel Works and Motorola have expressed interest in the commercial application of these materials. However, further kinetic enhancement, especially for the rehydriding process, is required to produce a material that is suitable for practical vehicular applications. It was therefore of interest to investigate whether further improvement of the kinetics of the reversible dehydriding of $\mathrm{NaAlH}_{4}$ could be achieved by other catalysts. Additionally, there is a thermodynamic limitation on the release of hydrogen from sodium aluminum hydride at the $80-100 \cdot \mathrm{C}$ temperatures that can be supplied from the exhaust of a PEM fuel cell. The 3.6 wt \% hydrogen released by first dehydriding reaction (in which $\mathrm{NaAlH}_{4}$ is converted to $\mathrm{Na}_{3} \mathrm{AlH}_{6}$ and $\mathrm{Al}$ ) establishes a practical plateau pressures in the range of 3-10 atm. However, in this temperature range the plateau pressure of the second reaction, in which $\left(\mathrm{Na}_{3} \mathrm{AlH}_{6}\right.$ is converted to $\mathrm{NaH}$ and $\left.\mathrm{Al}\right)$ is insufficient for utilization in a PEM fuel cell system. In order to harness the additional $1.9 \mathrm{wt} \%$ hydrogen available from this reaction 
at moderate temperatures, sodium must be at least partially substituted by an alternate cationic species that would favorably alter the thermodynamics of hydrogen release.

\section{Results}

Screening of Advanced Catalysts. We have explored the dehydriding and rehydriding kinetics of $\mathrm{NaAlH}_{4}$ doped with a variety of potential catalysts and catalysts precursors. The catalytic enhancement resulting from doping the hydride with the vanadium alkoxide complex, $\mathrm{V}(\mathrm{O})\left(\mathrm{OPr}_{3}^{\mathrm{i}}\right)_{3} \mathrm{Ti}_{3} \mathrm{Al}$, and $\mathrm{TiAl}$, were inferior in all respects to that produced by the titanium and zirconium catalyst precursors. We have, however, found two catalyst precursors that significantly improve the reversible dehydriding process. Most notably, we have discovered a new catalyst (composition can not be disclosed at this time due to proprietary reasons) whose principal effect is to vastly improve rehydriding kinetics. As seen in Figure 1, the kinetics of hydrogen uptake by dehydrided material are vastly

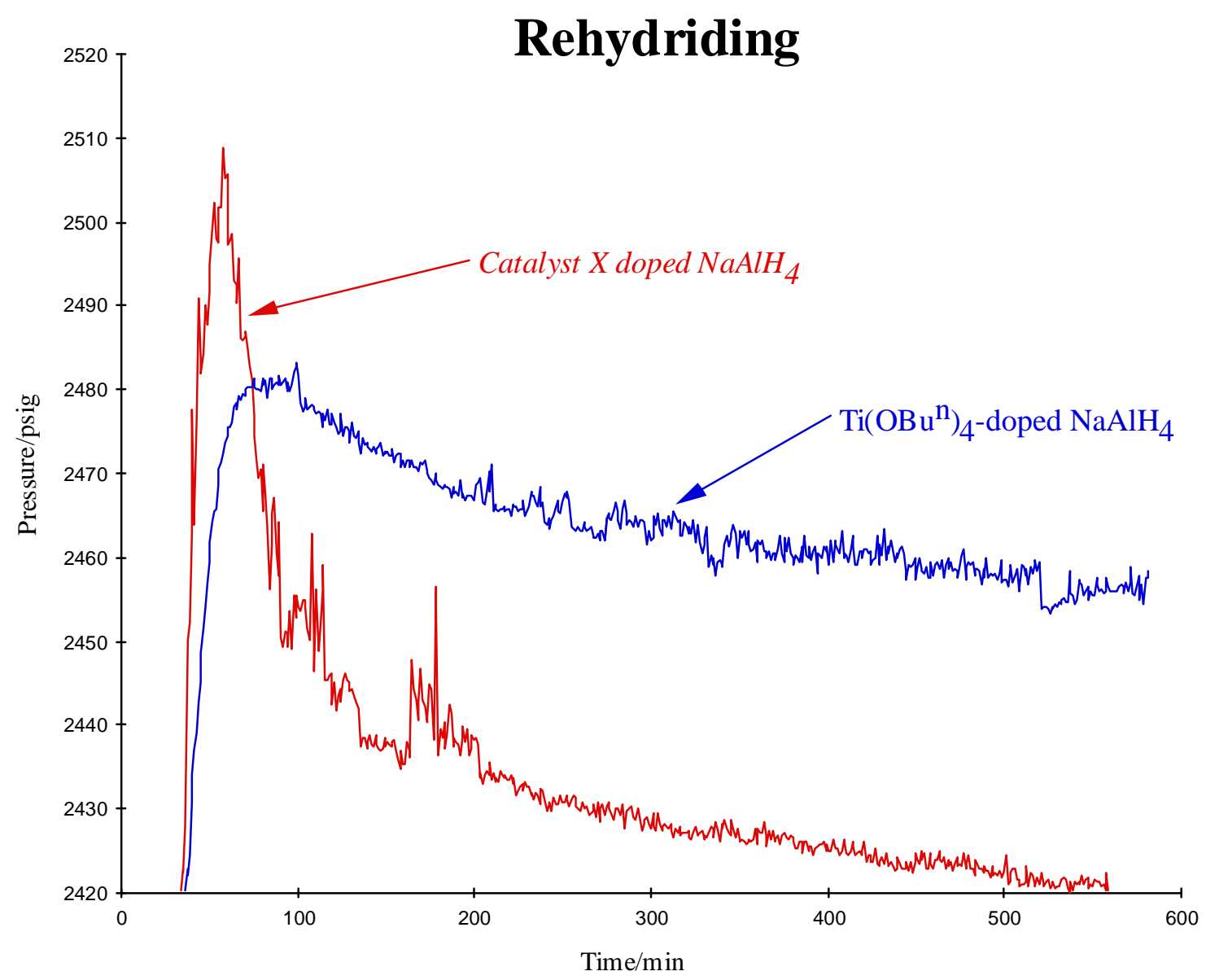

Figure 1. Comparison of hydrogen uptake by mixture of $\mathrm{NaH}+\mathrm{Al}$ doped with "catayst X" vs. $\mathrm{Ti}(\mathrm{OBu}) 4$.

improved in material doped with "catalyst X" beyond those resulting from doping with $\mathrm{Ti} / \mathrm{Zr}$. In the presence of the new catalyst, hydrogen recharging occurs in less than $2 \mathrm{~h}$ at 
$150 \cdot \mathrm{C}$ under $170 \mathrm{~atm}$ of hydrogen as opposed to the $10 \mathrm{~h}$ required for $\mathrm{NaAlH}_{4}$ that is doped with the titanium and/or zirconium alkoxide catalyst precursors. The combined benefit of the new, $\mathrm{Ti}$, and $\mathrm{Zr}$ catalysts have been realized in a sample of $\mathrm{NaAlH}_{4}$ that was doped with a ternary mixture of catalysts.

As mentioned above, large scale hydrogen cycling tests of $\mathrm{Ti} / \mathrm{Zr}$ doped $\mathrm{NaAlH}_{4}$ are being conducted in collaboration with Sandia National Laboratories. These studies have shown that the hydrogen evolved from hydride doped with $\mathrm{Ti}(\mathrm{OBu}) 4$ and/or $\mathrm{Zr}(\mathrm{Oi}-\mathrm{Pr}) 4$ contaminated with the gaseous hydrocarbons, butane and propane. Concerns that such contamination of hydrogen might impair the operation of a fuel cells lead us to explore the doping of the hydride with the inorganic catalyst precursor, TiCl4. As seen in Figure 2 , the catalytic enhancement of the dehydriding process was seen to be similar, and in fact slightly improved when $\mathrm{TiCl}_{4}$ was used in place of $\mathrm{Ti}(\mathrm{OBu}) 4$. Thus the problem of hydrocarbon contamination of the hydrogen evolved from catalytically enhanced $\mathrm{NaAlH}_{4}$ has been eliminated.

\section{TPD NaAlH4 with Varied Catalyst Precursers}

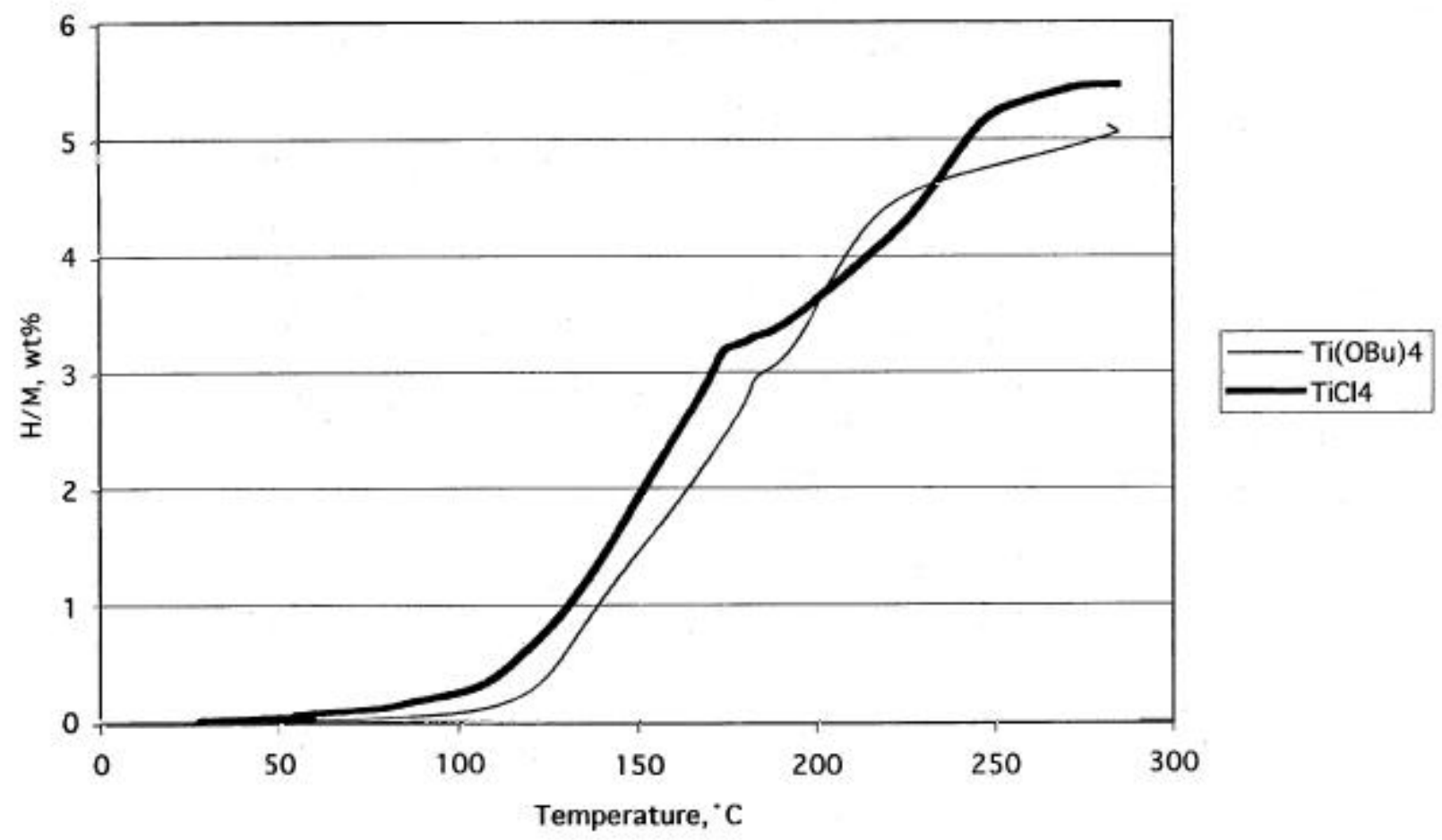

Figure 2. Comparison of the thermal programmed desorption $\left(2 \mathrm{C} \mathrm{min}^{-1}\right)$ of hydrogen from $\mathrm{NaAlH}_{4}$ doped with $\mathrm{TiCl}_{4}$ vs. $\mathrm{Ti}(\mathrm{OBu}) 4$.

\section{Synthesis and Evaluation of Salts with Partial Substitution of the Sodium} Cation. We have synthesized $\mathrm{Na}_{2} \mathrm{KAlH}_{6}$ through the mechanical alloying of a stoichiometric combination of $\mathrm{KH}$ and $\mathrm{NaAlH}_{4}$. Unfortunately, we have found that the 
potassium substitution results in an increase of the hydrogen desorption temperature to about $170 \cdot \mathrm{C}$ and decreases the hydrogen capacity by about $50 \%$. Similar attempts to prepare the magnesium substitution compound were unsuccessful. Our studies revealed that the material resulting from energetic mechanical alloying of either $\mathrm{MgH}_{2}$ or $\mathrm{Mg}$ powder with $\mathrm{NaAlH}_{4}$ is simply a mixture of $\mathrm{MgH}_{2}$ and $\mathrm{NaAlH}_{4}$.

\section{Conclusions}

Two important advances have been made in the development of improved catalysts for the reversible dehydriding of $\mathrm{NaAlH}_{4}$. We have discovered a new catalyst for the rehydriding of $\mathrm{NaH}$ and $\mathrm{Al}$ to $\mathrm{NaAlH}_{4}$. The kinetics of this process in the presence of this catalyst is improved by a factor of $\sim 5$ over that of Ti/Zr doped hydride. Thus the time required to recharge dehydrided material has been reduced from $10 \mathrm{~h}$ to $2 \mathrm{~h}$. Additionally, we have found that the problem of hydrocarbon contamination of the hydrogen evolved from catalytically enhanced $\mathrm{NaAlH}_{4}$ can be eliminated by doping the hydride with $\mathrm{TiCl}_{4}$ in place of $\mathrm{Ti}(\mathrm{OBu})_{4}$.

We have determined that partial substitution of sodium cation by potassium results in a lowering rather than the hoped for raising of the plateau pressure associated with the dehydriding of $\mathrm{X}_{3} \mathrm{AlH}_{6}$ to $\mathrm{XH}$ and $\mathrm{Al}$. Our attempts to prepare $\mathrm{NaMgAlH}_{6}$ through mechanical alloying techniques were unsuccessful. These results, in conjunction those previously obtained for Na2LiAlH6 (Bogdanovic and Schwickardi, 1997), indicate that the partial substitution of sodium by alkali metal or alkaline earth cations are not a means of raising the plateau pressure the $1.9 \mathrm{wt} \%$ hydrogen available from this reaction such that it could be utilized for fuel cell applications below $100 \bullet \mathrm{C}$.

\section{Future Work}

Further improvement in the rates of the dehydriding and, more crucially, the rehydriding of $\mathrm{NaAlH}_{4}$ are required in order for this material to achieve commercial viability. With this goal in mind, we plan to test a variety of bimetallic, aluminum-transition metal hydride complexes as catalysts for these processes. Our search for improved catalysts would be greatly aided by the characterization of the active catalysts in our materials and a fundamental understanding to of the mechanism of the fundamental dehydriding and rehydriding reactions. In order to gain such insight, we propose to study the reversible dehydriding of $\mathrm{NaAlH}_{4}$ by solid state nuclear magnetic resonance spectroscopy.

We have also found a class of catalysts that could provide the key to a practical hydrogen storage system based on the reversible dehydrogenation of cycloalkanes to arenes. Such a system meets the criteria of low cost and high hydrogen density $(\sim 7.0 \mathrm{wt}$ $\%)$. The PCP pincer complex, $\operatorname{IrH}_{2}\left\{\mathrm{C}_{6} \mathrm{H}_{3}-2,6-\left(\mathrm{CH}_{2} \mathrm{PBu}_{2}^{t}\right)_{2}\right\}$ is the first reported homogeneous catalysts for the dehydrogenation of cycloalkanes to arenes (Gupta et. al., 1997). Unlike the heterogeneous catalysts for this reaction, it shows appreciable activity at low concentrations at temperatures as low as $100 \bullet^{\circ}$. We have also found that the pincer complex also catalyzes the hydrogenation of arenes to cycloalkanes under 
moderate (10 atm) pressures of hydrogen. The two-way, hydrogenation/dehydrogenation activity of the catalyst suggests its application in a hydrogen storage system. The major obstacle to the practical application of the pincer catalyst is that pronounced product inhibition occurs after about $10 \%$ dehydrogenation of cycloalkanes. In order eliminate this problem we plan to synthesize and test an improved catalyst, $\operatorname{IrH}_{2}\left\{\mathrm{C}_{6} \mathrm{H}_{3}-2,6\right.$ $\left.\left(\mathrm{CH}_{2} \mathrm{AsBu}_{2}^{\mathrm{t}}\right)_{2}\right\}$.

\section{References}

Agarwal, R.K., J.S. Noh, J.A. Schwarz, and R. Davini, 1987. Carbon 25:219.

Bogdanovic, B. and M. Schwickardi, 1997. J. Alloys and Compounds , 1-9:253.

Carpetis, C. and W. Peshka, 1980. Int. J. Hydrogen Energy, 5: 539.

Dillon, A.C., K.M. Jones, T.A. Bekkedahl, C.H. Kiang, D.S. Bethune and M.J. Heben, 1997. Nature, 386:377.

Dymova, T.N., Y.M. Dergachev, V.A. Sokolov, and N.A. Grechanaya, 1975. Dokl. Akad. Nauk USSR, 224:591.

Dymova, T.N., N.G. Eliseeva, S.I. Bakum, and Y.M. Dergachev, 1974. Dokl. Akad. Nauk USSR, 215:1369.

Gupta, M., C. Hagen, W.C. Kaska, R.E. Cramer, C.M. Jensen, 1997. J. Am. Chem. Soc., 119: 840 .

Jensen, C.M., R. Zidan, N. Mariels, A. Hee, C. Hagen,1999. Int. J. Hydrogen Energy, 24:461.

Sandrock, G., S. Suda, and L. Schlapbach, 1992. Topics in Appl. Phys., 67:197.

Sandrock, G. 1995. Application of Hydrides in Hydrogen Energy Systems (ed Yurum), 253-280. Netherlands: Kluwer Academic Publishers.

Suda, S. and G. Sandrock, 1994. Z. Phys. Chem., 183:149.

Zidan, R.A., S. Takara, A.G. Hee, C.M. Jensen, 1999. J. Alloys and Compounds, 285:119. 